\title{
STUDI KEANEKARAGAMAN JENIS BAMBU DI DESA TANJUNG TERDANA BENGKULU TENGAH
}

\author{
Resti Weni Hastuti ${ }^{{ }^{*},}$ Ariefa Primair Yani ${ }^{1}$, Irwandi Ansori ${ }^{1}$ \\ ${ }^{1}$ Program Studi Pendidikan Biologi, Fakultas Keguruan dan Ilmu Pendidikan, Universitas Bengkulu \\ Email: restibk103@gmail.com
}

\begin{abstract}
Abstrak
Tumbuhan bambu merupakan tumbuhan yang memiliki banyak manfaat. Hal ini terlihat dari masih banyak ditemukannya tumbuhan ini di kehidupan sehari-hari. Penelitian mengenai studi keanekaragaman bambu ini dilakukan di Desa Tanjung Terdana Kabupaten Bengkulu Tengah, yang bertujuan untuk mengetahui keanekaragaman tumbuhan bambu di Desa Tanjung Terdana Bengkulu Tengah. Pengambilan sampel dilakukan dengan menggunakan metode jelajah. Pencatatan langsung di lapangan dilakukan untuk banyak rumpun, keterangan botani, nama daerah, dan data ekologi. Berdasarkan hasil penelitian yang telah dilakukan, ditemukan 4 marga bambu dengan 8 jenis yaitu Gigantochloa pseudoarundinaceae, Bambusa multiplex, Dendrocalamus asper, Gigantochloa serik, Gigantochloa robusta, Schyzotyum lima, Bambusa vulgaris var.vulgaris, dan Gigantochloa apus.
\end{abstract}

Kata Kunci : keanekaragaman jenis, bambu, desa Tanjung Terdana

\begin{abstract}
Bamboo are plants that have many benefits, so are easily found in daily lifes. The study of bamboo diversity was conducted in Tanjung Terdana village of Bengkulu Tengah Regency, which aimed to determined the diversity of bamboo plants in Tanjung Terdana Bengkulu Tengah. Sampling was conducted by using roaming method. Field observation was conducted for number of clumps, botanical explanations, regional names, and ecological data. This research has concluded that the type of bamboo in the Tanjung Terdana village Bengkulu Tengah consists of 4 genera belonging to 8 species of bamboo, namely Gigantochloa pseudoarundinaceae, Bambusa multiplex, Dendrocalamus asper, Gigantochloa serik, Gigantochloa robusta, Schyzotyum lima, Bambusa vulgaris var.vulgaris, and Gigantochloa apus.

Keywords: species diversity, bamboo, desa Tanjung Terdana
\end{abstract}




\section{PENDAHULUAN}

Bambu tergolong famili Poaceae (rumput-rumputan) disebut juga Giant Grass (rumput raksasa), berumpun dan terdiri dari sejumlah batang (buluh) yang tumbuh secara bertahap, dari mulai rebung, batang muda dan sudah dewasa pada umur 3-4 tahun. Batang bambu berbentuk silindris, berbuku-buku/beruas-ruas berongga, berdinding keras, pada setiap buku terdapat mata tunas atau cabang (Andoko, 2003). Morfologi bambu dapat dilihat berdasarkan karakteristik pada akar rimpang yang terdapat dibawah tanah dan membentuk sistem percabangan. Batang berupa buluh yang terdiri atas ruas dan buku-buku. Pelepah buluh merupakan hasil modifikasi daun yang menempel pada setiap ruas, yang terdiri dari daun pelepah buluh, kuping pelepah buluh, dan ligula. Percabangan umumnya terdapat pada nodus. Helaian daun bambu mempunyai urat daun yang sejajar. Helaian daun dihubungkan dengan pelepah oleh tangkai daun. Pelepah daun dilengkapi oleh kuping pelepah dan ligula (Widjaja, 2001).

Bambu dapat tumbuh dengan baik pada berbagai jenis tanah pada ketinggian 0-2000 $\mathrm{m}$ di atas permukaan laut (dpl). Bahkan, bambu dapat tumbuh pada tanah marginal yang kurang subur sekalipun. Bambu termasuk jenis tanaman yang memiliki pertumbuhan sangat cepat. Dalam waktu sekitar 3 tahun sejak ditanam, sebatang bambu sudah dapat membentuk rumpun yang sangat rapat (Andoko, 2003).

Menurut Dephut (1992) dalam Yani, (2012), pertumbuhan bambu tidak terlepas dari pengaruh kondisi lingkungan tempat tumbuh. Adapun faktor-faktor lingkungan yang berkaitan dengan syarat tumbuh

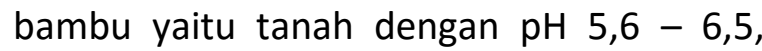
ketinggian tempat $0-2000 \mathrm{~m} \mathrm{dpl}$, suhu 8,8 $-36^{\circ} \mathrm{C}$, curah hujan tahunan minimal 1.020 $\mathrm{mm}$, dan kelembaban $80 \%$. Bambu dapat tumbuh pada tanah yang bereaksi masam dengan $\mathrm{pH}$ 3,5 dan umumnya menghendaki tanah yang $\mathrm{pH}$ nya 5,0 sampai 6,5 . Pada tanah yang subur, tanaman bambu akan tumbuh dengan baik karena kebutuhan makanan bagi tanaman tersebut akan terpenuhi (Soedjono dan Hartanto, 1994).

Desa Tanjung Terdana merupakan salah satu desa dari 12 desa yang terdapat di wilayah Kecamatan Pondok Kubang Kabupaten Bengkulu Tengah Provinsi Bengkulu dengan luas desa yaitu $2.700 \mathrm{Ha}$. Terdiri dari wilayah persawahan dengan luas $1.116 \mathrm{Ha}$ dan daratan seluas $1.584 \mathrm{Ha}$. Kawasan daratan yang memiliki luas 1.584 $\mathrm{Ha}$ tersebut terdiri atas hutan Negara (Taman Hutan Raya seluas $650 \mathrm{Ha}$ dan Pemukiman warga seluas $934 \mathrm{Ha}$ ).

Berdasarkan data Badan

Pemberdayaan Masyarakat Provinsi Bengkulu (2013), Desa Tanjung Terdana memiliki kondisi tanah yang datar serta berbukit dengan suhu rata-rata harian yaitu $27-29^{\circ} \mathrm{C}$. Warna tanah sebagian besar berwarna kuning serta memiliki tekstur seperti pasir.

Penelitian ini dilakukan bertujuan untuk mengetahui keanekaragaman bambu di desa Tanjung Terdana Kabupaten Bengkulu Tengah.

\section{METODE PENELITIAN}

Penelitian ini dilakukan di Desa
Tanjung Terdana Bengkulu Tengah.
Pengambilan sampel dilakukan dengan
menggunakan metode jelajah, yaitu dengan
cara menyusuri jalan setapak. Pada
penelitian ini peneliti mengambil 3 titik
lokasi penelitian yaitu di pinggir sawah, di
pinggir sungai dan di sekitar kebun. Jadi
pengambilan sampel ini dilakukan dengan
menyusuri ketiga lokasi tersebut.


Pemilihan lokasi sampling dilakukan di ketiga titik lokasi ini dikarenakan populasi tumbuhan bambu yang ada di Desa Tanjung Terdana terletak di sekitar area sawah, pinggir sungai dan kebun. Hal ini sesuai dengan observasi awal peneliti pada saat melakukan studi pendahuluan di Desa Tanjung Terdana untuk melihat dan mengenali tata letak lokasi yang akan dijelajah.

Pengamatan dilakukan pada setiap individu tumbuhan bambu yang ditemukan di lokasi penelitian. Jenis bambu yang ditemukan difoto dan diambil untuk dikoleksi (herbarium). Sebelum pengambilan sampel, dilakukan pengamatan dan pencatatan terhadap ciriciri penting dari tumbuhan bambu yang akan berubah atau hilang setelah di keringkan (dibuat herbarium), seperti warna dan jenis miang/bulu dari bambu tersebut.

Pengamatan data lapangan dilakukan menggunakan instrumen lembar observasi lapangan. Bagian tumbuhan bambu yang diamati adalah rebung, batang, pelepah, percabangan dan daun. Setiap sampel yang telah diamati ciri morfologinya dicatat dalam tabel tabulasi ciri yang kemudian difoto sebagai data dokumentasi serta pencatatan jumlah rumpun bambu yang ditemukan.

Pada penelitian ini alat yang digunakan adalah kamera, cutter, gunting, alat tulis, tali rafia, parang, pisau, gergaji, meteran, sasak, penggaris, lem, karton, kertas koran, kardus, isolasi, jarum, benang putih, kaca pembesar, jangka sorong, lem kertas, plastik bening dan double tip, sedangkan bahan yang digunakan adalah spritus putih dan tumbuhan bambu.

\section{HASIL DAN PEMBAHASAN}

Kabupaten Bengkulu Tengah terletak pada ketinggian tempat 15 - 20 meter dari permukaan laut, dengan suhu udara berkisar $27^{\circ} \mathrm{C}-30^{\circ} \mathrm{C}$, kelembaban udara 60 - $70 \%$, dan suhu tanah $29^{\circ} \mathrm{C}-31^{\circ} \mathrm{C}$. Menurut Andoko (2003), tumbuhan bambu dapat tumbuh dengan baik pada ketinggian 0 - $2000 \mathrm{~m}$ dpl, dengan suhu udara 8,8 - 30 ${ }^{\circ} \mathrm{C}$ dan kelembaban udara $50-80 \%$. Hal ini berarti kondisi lingkungan Kabupaten Bengkulu Tengah memenuhi syarat untuk pertumbuhan bambu. Tabel 1 menunjukkan jenis-jenis tumbuhan bambu yang ditemukan di Desa Tanjung Terdana Bengkulu Tengah.

Tabel 1 Jenis bambu yang ditemukan di Desa Tanjung Terdana Kabupaten Bengkulu Tengah

\begin{tabular}{|c|c|c|c|}
\hline \multirow[t]{2}{*}{ Marga } & Jenis & Nama Lokal & \multirow{2}{*}{$\begin{array}{c}\sum \text { Rum } \\
\text { pun }\end{array}$} \\
\hline & $\begin{array}{l}\text { Bambusa } \\
\text { multiplex }\end{array}$ & $\begin{array}{l}\text { Bambu aur } \\
\text { cina }\end{array}$ & \\
\hline \multirow[t]{2}{*}{ Bambusa } & $\begin{array}{l}\text { Bambusa } \\
\text { vulgaris } \\
\text { var.vulgaris }\end{array}$ & Bambu aur & 7 \\
\hline & $\begin{array}{l}\text { Gigantochlo } \\
\text { a } \\
\text { pseudoarun } \\
\text { dinacea }\end{array}$ & Bambu dabuk & 6 \\
\hline \multirow[t]{3}{*}{ Gigantochloa } & $\begin{array}{l}\text { Gigantochlo } \\
\text { a serik }\end{array}$ & Bambu serik & 13 \\
\hline & $\begin{array}{l}\text { Gigantochlo } \\
\text { a robusta }\end{array}$ & Bambu mayan & 10 \\
\hline & $\begin{array}{l}\text { Gigantchloa } \\
\text { apus }\end{array}$ & Bambu tali & 2 \\
\hline Schyzotyum & $\begin{array}{l}\text { Schyzotyum } \\
\text { lima }\end{array}$ & $\begin{array}{l}\text { Bambu } \\
\text { mupe/suling }\end{array}$ & 7 \\
\hline $\begin{array}{c}\text { Dendrocalam } \\
\text { us } \\
\end{array}$ & $\begin{array}{l}\text { Dendrocala } \\
\text { mus asper }\end{array}$ & $\begin{array}{l}\text { Bambu } \\
\text { betung }\end{array}$ & 5 \\
\hline \multicolumn{2}{|c|}{ Berdasarkan } & hasil & studi \\
\hline \multicolumn{2}{|c|}{ keanekaragaman jenis } & bambu di & Desa \\
\hline \multicolumn{4}{|c|}{ Tanjung Terdana Kabupaten } \\
\hline \multicolumn{4}{|c|}{$\begin{array}{l}\text { Tengah, terdapat perbedaan dan } \\
\text { persamaan ciri karakteristik morfologi dari } \\
\text { tiap jenis bambu. Yang membedakan genus }\end{array}$} \\
\hline Schizostach & deng & genus & ainnya \\
\hline
\end{tabular}


adalah ukuran cabangnya. Genus Schizotachyum memiliki ukuran cabang yang sama besar dan batangnya memiliki ruas paling panjang yaitu $\geq 50 \mathrm{~cm}$.

Ciri khas dari genus Bambusa adalah permukaan batangnya yang mengkilap licin, memiliki posisi daun pelepah yang tegak dan memiliki sistem percabangan yang tidak sama besar. Hal ini sesuai dengan ciri kelompok Bambusa menurut Arinasa (2004) bahwa ciri khas dari kelompok Bambusa ialah daun pelepah buluhnya tegak dan batangnya licin.

Ciri khas dari genus Gigantochloa ialah permukaan batang berlapis lilin, posisi daun pelepah terkeluk balik, sistem percabangan memiliki satu cabang yang lebih besar daripada cabang lainnya. Hal ini juga sesuai dengan ciri khas genus Gigantochloa. Menurut Widjaja (2001), posisi daun pelepah buluh terkeluk terbalik dan memiliki sistem percabangan memiliki satu cabang yang lebih besar daripada cabang lainnya.

Ciri khas dari genus Dendrocalamus adalah ukuran diameter serta ketebalan dinding batangnya yang paling besar dari genus bambu yang lain serta memiliki sistem percabangan yang tidak sama besar. Sehingga menurut Irawan, dkk (2006) kelompok Dendrocalamus memang disebut Giant Tropical Clumping Bamboos karena ukurannya yang raksasa dibandingkan kelompok bambu yang lain.

Perberbedaa panjang ruas, diameter batang, bentuk percabangan dan posisi daun pelepah batang dapat digunakan untuk mengelompokkan jenis-jenis bambu. Beberapa jenis bambu memiliki ruas panjang seperti pada genus Schyzotyum yang memiliki ruas yang lebih panjang dibandingkan dengan genus lainnya. Genus Dendrocalamus mempunyai diameter yang lebih besar dibandingkan dengan jenis bambu lainnya.

Cabang dapat digunakan sebagai ciri penting untuk membedakan genus bambu. Pada genus Bambusa, Dendrocalamus, Gigantochloa, sistem percabangannya mempunyai satu percabangan dengan satu cabang yang lebih besar dibandingkan dengan cabang lainnya. Sedangkan pada genus Schyzotyum mempunyai cabang yang sama besar.

Posisi daun pelepah batang pada jenis bambu berbeda-beda. Ada yang tegak, terkeluk balik, menyebar dan menyadak seperti pada genus Bambusa yang memiliki posisi daun pelepah batang yang tegak sedangkan pada genus Gigantochloa, Dendrocalamus, dan Schyzotyum posisi daun pelepah batangnya terkeluk balik (Widjaja, 2001).

Berikut ini merupakan deskripsi jenis bambu yang ditemukan di Desa Tanjung Terdana Bengkulu Tengah :

\section{1) Bambu dabuk (Gigantochloa pseudoarundinacea)}

Rumpun rapat. Rebung berukuran besar, kuncup berwarna hijau muda dengan miang berwarna coklat tua, bentuk kuncup panjang seperti jarum. Batang berwarna hijau tua dengan sedikit garis kuning sejajar, tinggi batang diperkirakan mencapai 7-14,5 $m$ dari permukaan tanah sampai pucuk batang, permukaan batang dilapisi lilin putih, panjang ruas $20-47 \mathrm{~cm}$, diameter batang 2-4 cm, ketebalan batang 3-9 $\mathrm{mm}$. Percabangan satu lebih besar daripada cabang lainnya, dengan jumlah cabang 6-12 cabang dalam satu ruas. Pelepah warna miang coklat tua, mudah luruh, panjang bulu kejur 1-2 mm, memiliki ligula dengan bentuk tepi ligula rata, posisi daun pelepah terkeluk balik. Daun berwarna hijau, bentuk pita, permukaan bagian bawah berbulu, 
panjang daun 21,8-32 cm, lebar daun 2,54,3 cm, panjang bulu kejur 1-2 $\mathrm{mm}$, panjang ligula 1-3 $\mathrm{mm}$ dengan bentuk tepi ligula bergerigi.

2) Bambu aur cina (Bambusa multiplex)

Rumpun sangat rapat dan padat. Rebung berukuran kecil, kuncup berwarna hijau kekuningan tanpa miang, bentuk kuncup panjang seperti jarum. Batang berwarna hijau tua, tinggi batang diperkirakan mencapai 4-7 $\mathrm{m}$ dari permukaan tanah sampai pucuk batang, permukaan batang mengkilap licin, panjang ruas $15-40 \mathrm{~cm}$, diameter batang 0,4-1 cm, ketebalan batang 2-5 $\mathrm{mm}$. Percabangan satu lebih besar daripada cabang lainnya, dengan jumlah cabang 7-15 dalam satu ruas. Pelepah warna miang coklat, mudah luruh, panjang bulu kejur 0,2-1 mm, memiliki ligula dengan bentuk tepi ligula bergerigi, posisi daun pelepah tegak. Daun berwarna hijau tua, berukuran kecil dibandingkan dengan daun bambu lainnya, panjang daun 5-13 cm, lebar daun 0,4-1,5 $\mathrm{cm}$, panjang bulu kejur 0,4-0,9 mm, panjang ligula 0,4-1 $\mathrm{mm}$ dengan bentuk ligula bergerigi.

3) Bambu betung (Dendrocalamus asper)

Rumpun kurang rapat. Rebung berukuran besar, kuncup berwarna hijau keunguan dengan miang berwarna coklat tua, bentuk kuncup panjang seperti jarum. Batang berwarna hijau tua dengan totoltotol putih, tinggi batang diperkirakan mencapai 6,4-10 m dari permukaan tanah sampai pucuk batang, permukaan batang berlapis lilin putih, panjang ruas $29-42 \mathrm{~cm}$, diameter batang 6-9 cm, ketebalan batang 15-20 mm. Percabangan satu lebih besar daripada cabang lainnya, dengan jumlah cabang 5-11 cabang dalam satu ruas. Pelepah warna miang hitam, mudah luruh, panjang bulu kejur 4-7 mm, memiliki ligula dengan bentuk tepi ligula bergerigi, posisi daun pelepah terkeluk balik. Daun berwarna hijau, bentuk pita, permukaan lebar dengan tulang daun menonjol, panjang daun $18-30 \mathrm{~cm}$, lebar daun $2,5-8$ $\mathrm{cm}$, panjang bulu kejur 1,3-2 $\mathrm{mm}$, panjang ligula 2-2,5 $\mathrm{mm}$ dengan bentuk tepi ligula rata.

4) Bambu serik (Gigantochloa serik)

Rumpun rapat. Rebung berukuran besar, kuncup berwarna hijau keunguan dengan miang berwarna hitam, bentuk kuncup panjang seperti jarum. Batang berwarna hijau terang, tinggi batang diperkirakan mencapai 5-13 m dari permukaan tanah sampai pucuk batang, permukaan batang dilapisi lilin putih, panjang ruas $25-44 \mathrm{~cm}$, diameter batang 13,5 cm, ketebalan batang 1,5-6 $\mathrm{mm}$. Percabangan satu lebih besar daripada cabang lainnya, dengan jumlah cabang 6-15 cabang dalam satu ruas. Pelepah warna miang hitam,mudah luruh, panjang bulu kejur 1,5-3 mm, memiliki ligula dengan bentuk tepi ligula rata, posisi daun pelepah terkeluk balik. Daun berwarna hijau, panjang daun 20-30 cm, lebar daun 1,7-2,2 $\mathrm{cm}$, panjang bulu kejur 1,5-3 $\mathrm{mm}$, panjang ligula 0,6-2,3 $\mathrm{mm}$ dengan bentuk tepi ligula rata.

5) Bambu mayan (Gigantochloa robusta)

Rumpun rapat. Rebung berukuran besar, kuncup rebung berwarna hijau muda dengan miang berwarna hitam, bentuk kuncup panjang seperti jarum. Batang berwarna hijau tua, tinggi batang diperkirakan mencapai 7-14 $\mathrm{m}$ dari permukaan tanah sampai pucuk batang, permukaan batang dilapisi lilin putih, panjang ruas $25-44 \mathrm{~cm}$, diameter batang 2-4 $\mathrm{cm}$, ketebalan batang 3,5-10 $\mathrm{mm}$. Percabangan satu lebih besar daripada cabang lainnya, dengan jumlah cabang 7-11 cabang dalam satu ruas. Pelepah warna miang hitam, mudah luruh, panjang bulu 
kejur 1-3 mm, memiliki ligula dengan bentuk tepi ligula rata, posisi daun pelepah terkeluk balik. Daun berwarna hijau, panjang daun $23,5-33 \mathrm{~cm}$, lebar daun $1,7-3$ $\mathrm{cm}$, panjang bulu kejur 2-3 $\mathrm{mm}$, panjang ligula 1-2,4 $\mathrm{mm}$ dengan bentuk tepi ligula bergerigi.

6) Bambu mupe/suling (Schyzotyum lima)

Rumpun kurang padat. Rebung berukuran kecil, kuncup rebung berwarna hijau keunguan dengan miang berwarna coklat tua, bentuk kuncup panjang seperti jarum. Batang berwarna hijau kekuningan, tinggi batang diperkirakan mencapai 5-13 m dari permukaan tanah sampai pucuk batang, permukaan batang berlapis lilin, panjang ruas $50-120 \mathrm{~cm}$, diameter batang 2$3 \mathrm{~cm}$, ketebalan batang 2,9-4,5 $\mathrm{mm}$. Percabangan satu lebih besar daripada cabang lainnya, dengan jumlah cabang 1850 cabang dalam satu ruas. Pelepah warna miang coklat, tidak mudah luruh, panjang bulu kejur 1-4,5 mm, memiliki ligula dengan bentuk tepi ligula bergerigi, posisi daun pelepah terlekuk balik. Daun berwarna hijau muda, panjang daun $15-33 \mathrm{~cm}$, lebar daun 2,4-3 cm, panjang bulu kejur 2-4 mm, panjang ligula 2-4 $\mathrm{mm}$ dengan bentuk tepi ligula rata.

7) Bambu aur (Bambusa vulgaris var.vulgaris)

Rumpun tidak terlalu rapat. Rebung berukuran besar, kuncup rebung berwarna hijau kekuningan dengan miang berwarna hitam, bentuk kuncup bulat meruncing. Batang berwarna hijau pucat, tinggi batang diperkirakan mencapai 5-13 m dari permukaan tanah sampai pucuk batang, permukaan batang mengkilap licin, panjang ruas $22-42 \mathrm{~cm}$, diameter batang $2,4-5 \mathrm{~cm}$, ketebalan batang 5-10 mm. Percabangan satu lebih besar daripada cabang lainnya dengan jumlah cabang 4-7 cabang dalam satu ruas. Pelepah warna miang hitam, mudah luruh, panjang bulu kejur 1,5-3,4 $\mathrm{mm}$, memiliki ligula dengan bentuk tepi ligula bergerigi, posisi daun pelepah tegak. Daun berwarna hijau, panjang daun 15-33 $\mathrm{mm}$, lebar daun 2-3,2 cm, panjang bulu kejur 1,2-3,2 mm, panjang ligula 2-3 mm dengan bentuk tepi ligula bergerigi.

8) Bambu tali (Gigantochloa apus)

Rumpun rapat. Rebung berukuran besar, kuncup rebung berwarna hijau keunguan dengan miang berwarna coklat tua, bentuk kuncup bulat meruncing. Batang berwarna hijau tua, tinggi batang diperkirakan mencapai 7-15 $\mathrm{m}$ dari permukaan tanah sampai pucuk batang, permukaan batang dilapisi lilin putih, panjang ruas $26-45 \mathrm{~cm}$, diameter batang 2-4 $\mathrm{cm}$, ketebalan batang 4-10 $\mathrm{mm}$. Percabangan satu lebih besar daripada cabang lainnya, dengan jumlah cabang 5-11 cabang dalam satu ruas. Pelepah warna miang coklat tua, mudah luruh, panjang bulu kejur 1,8-4 mm, memiliki ligula dengan bentuk tepi ligula rata, posisi daun pelepah terkeluk balik. Daun berwarna hijau tua, panjang daun 22-33 cm, lebar daun 2,1-3,1 $\mathrm{cm}$, panjang bulu kejur 1,8-4 $\mathrm{mm}$, memiliki ligula dengan bentuk tepi ligula rata.

\section{PENUTUP}

\section{Simpulan}

Berdasarkan hasil studi keanekaragaman tumbuhan bambu di Desa Tanjung Terdana Bengkulu Tengah, diperoleh 4 marga dengan 8 jenis tumbuhan bambu yaitu : genus Dendrocalamus dengan spesies Dendrocalamus asper, genus Bambusa dengan spesies Bambusa multiplex dan Bambusa vulgaris var. vulgaris,genus Schizostachyum dengan spesiesSchyzotyum lima dan genus Gigantochloa dengan spesies Gigantochloa 
pseudoarundinaceae, Gigantochloa serik, Gigantochloa robusta, dan Gigantochloa apus.

\section{Saran \\ Perlu dilakukan penelitian lebih lanjut mengenai pengembangan LKS berdasarkan hasil studi keanekaragaman ini, khususnya pada tumbuhan bambu. Hal ini bertujuan untuk memperkaya dan menambah wawasan mengenai pengembangan LKS yang didesain berdasarkan hasil studi keanekaragaman tumbuhan bambu.}

\section{DAFTAR PUSTAKA}

Arinasa, Ida Bagus Ketut. 2004. Keanekaragaman dan Penggunaan Jenis-jenis Bambu di Desa Tigawasa, Bali. Bali : UPT Balai Konservasi Tumbuhan Kebun Raya "Eka Karya" Bali-LIPI.

Andoko, Agus. 2003.Budi daya Bambu Rebung. Yogyakarta : Penerbit Kanisius.
BPMPB. 2013. Profil Desa. Bengkulu Tengah : Badan Pemberdayaan Masyarakat Provinsi Bengkulu

Irawan, B., Rahayuningsih, S. R., Kusmoro, J. 2006. Keanekaragaman Jenis Bambu Di Kabupaten Sumedang Jawa Barat. Sumedang: Jurusan Biologi FMIPA Universitas Padjadjaran.

Soedjono dan Hartanto. 1994. Budidaya Bambu. Semarang : Dahara Prize

Widjaja, E. A. 2001a. Identikit Jenis-Jenis Bambu Di Jawa. Bogor: Puslitbang Biologi-LIPI.

Yani, A.P. 2012. Keanekaragaman Dan Populasi Bambu Di Desa Talang Pauh Bengkulu Tengah. Jurnal Exacta, Vol. X No. 1 Juni 2012 ISSN 1412-3617. Bengkulu: Prodi Pendidikan Biologi FKIP Universitas Bengkulu. 